\title{
Soroneutralização e imunofluorescência utilizando anticorpos monoclonais no diagnósti- co rápido de infecções pelo herpesvírus bovino tipos 1 e 5 (BHV-1 e BHV-5) ${ }^{1}$
}

\author{
Serum neutralizing and fluorescent antibody assays using monoclonal antibodies in rapid diagnostic tests \\ for bovine herpesvirus types 1 (BHV-1) and 5 (BHV-5) infections
}

\section{Cintia Farias Kunrath ${ }^{2}$ Fernanda Silveira Flores Vogel ${ }^{3} \quad$ Ivomar Oldoni $^{2}$ Eduardo Furtado Flores ${ }^{4}$ Rudi Weiblen ${ }^{5}$ Renata Dezengrini $^{6}$ Fabrício Dias Torres ${ }^{6}$ Kleitton Adolfo Pan ${ }^{6}$}

\section{RESUMO}

Anticorpos monoclonais (AcMs) produzidos com uma amostra brasileira do herpesvírus bovino tipo 5 ( $\mathrm{BHV}$ 5) foram utilizados na adaptação e padronização de técnicas rápidas para o diagnóstico de infecções pelo $\mathrm{BHV}-1$ e $\mathrm{BHV}$ 5. A detecção de antígenos virais por imunofluorescência em células descamativas (IFCD) foi comparada com o isolamento viral, em secreções nasais de 16 bezerros, sendo 6 inoculados com o BHV-1 e 10 com o BHV-5. De 203 amostras testadas, $182(89,6 \%)$ apresentaram resultados concordantes nos dois testes (143 positivas; 39 negativas). Comparando-se com o isolamento, a IFCD apresentou sensibilidade de $96,6 \%$, especificidade de $70,9 \%$, e precisão de $89,6 \%$. Os AcMs também foram utilizados para detectar antígenos do BHV-5 em impressões frescas do cérebro de bezerros acometidos de enfermidade neurológica e em células de cultivo utilizadas na técnica de soroneutralização (SN), permitindo a obtenção dos resultados em 24 horas. A técnica, denominada de soroneutralização rápida (SNR), apresentou sensibilidade de 97,3\%; especificidade de 95,5\% e precisão de $96,2 \%$ em comparação com a SN tradicional; $e$ sensibilidade de $94,7 \%$, especificidade de $97,3 \%$ e precisão de 96,1\% em comparação com um ELISA comercial. Esses resultados demonstram que esses AcMs podem ser muito úteis para uso em técnicas rápidas de diagnóstico de infecções suspeitas de BHV-1 ou de BHV-5, sobretudo em situações de surto, quando a tomada de decisões adequadas depende de um diagnóstico rápido e confiável.

Palavras-chave: herpesvírus bovino, $B H V-1, B H V-5$, diagnóstico, anticorpos monoclonais.

\begin{abstract}
Monoclonal antibodies ( $m A b s)$ produced to a Brazilian isolate of bovine herpesvirus type 5 (BHV-5) were used to standardize rapid tests for the diagnostic of BHV-1 and BHV-5 infections. The detection of viral antigens by immunofluorescence in descamative cells (IFDC) was compared to virus isolation in nasal secretions of 16 calves inoculated with BHV-1 $(n=6)$ or BHV-5 (n=10). One hundred and sixty two out of 203 specimens (89.6\%) had identical results in both assays (143 positive; 39 negative); the IFDC assay showing a sensitivity of $96.6 \%$, specificity of $70.9 \%$ and precision of $89.6 \%$. The mAbs were also used to detect BHV-5 antigens in fresh brain smears of calves from outbreaks of neurological disease; and in cell cultures used in a virus neutralizing (VN) test, allowing the obtention of results in 24 hours. The rapid virus neutralizing test $(R V N)$ showed a sensitivity of $97.3 \%$, specificity of $95.5 \%$ and precision of $96.2 \%$ comparing to the standard VN test; and a sensitivity of $94.7 \%$, specificity of $97.3 \%$ and precision of $96.1 \%$ as compared to a commercial ELISA. These results demonstrate that these $m A b s$ are useful in rapid diagnostic tests, which may be very important in field outbreaks, when taking adequate decisions depends on rapid and reliable diagnostic tests.
\end{abstract}

Key words: bovine herpesvirus, BHV-1, BHV-5, diagnostic, monoclonal antibodies.

\footnotetext{
${ }^{1}$ Trabalho realizado com suporte financeiro do Conselho Nacional de Desenvolvimento Tecnológico (CNPq), Coordenação de Aperfeiçoamento de Pessoal de Nível Superior (Capes) e Finep (Pronex em Virologia Veterinária, 215/96).

${ }^{2}$ Médico Veterinário, mestrando em Medicina Veterinária, UFSM.

${ }^{3}$ Médico Veterinário, MSc, Doutor, Professor substituto do Departamento de Medicina Veterinária Preventiva (DMVP) da UFSM.

${ }^{4}$ Médico Veterinário, MSc, Doutor, Departamento de Medicina Veterinária Preventiva, Centro de Ciências Rurais, UFSM, 97105-900, Santa Maria, RS. Bolsista do CNPq (520758/96-0). Fone/fax: 55-220-8034. E-mail: flores@ ccr.ufsm.br. Autor para correspondência.

${ }_{5}^{5}$ Médico Veterinário, MSc, Doutor, Departamento de Medicina Veterinária Preventiva e Departamento de Microbiologia e Parasitologia, UFSM. Bolsista do CNPq (520161/97-1).

${ }^{6}$ Estudantes do curso de Medicina Veterinária, UFSM, Estagiário, (R.D.) Bolsista de Iniciação Científica, FAPERGS (F.D.T.) e CNPq (KAP).
} 


\section{INTRODUÇÃO}

Os herpesvírus bovinos tipos 1 (BHV-1) e 5 (BHV-5) são vírus DNA, envelopados, membros da família Herpesviridae, subfamília Alphaherpesvirinae, gênero varicellovirus (ROIZMAN et al., 1992). A infecção pelo BHV-1 pode resultar em doença respiratória (rinotraqueíte infecciosa bovina, IBR), genital (vulvovaginite pustular infecciosa, IPV; ou balanopostite pustular infecciosa, IBP) e abortos (KAHRS, 2001), enquanto o BHV-5 tem sido associado a meningoencefalite de curso geralmente fatal (STUDDERT, 1989). Ambos os vírus são neurotrópicos, mas apenas o BHV-5 é capaz de replicar eficientemente no sistema nervoso central (CNS) e causar meningoencefalite (MEYER et al., 2001).

A infecção pelo BHV-1 tem distribuição mundial, com exceção de alguns países europeus que erradicaram a infecção (KAHRS, 2001). A distribuição geográfica da infecção pelo BHV-5 não é bem conhecida, principalmente devido à reatividade sorológica cruzada com o BHV-1. No entanto, surtos de doença neurológica associados a esse vírus já foram descritos na Austrália (FRENCH, 1962), Argentina (CARRILLO et al., 1983), Estados Unidos (EUGSTER et al., 1974), Europa (BARTHA et al., 1969) e Brasil (WEIBLEN et al., 1989).

O BHV-1 e o BHV-5 são semelhantes entre si nos aspectos morfológicos, biológicos e moleculares e são antigenicamente relacionados, o que pode ser demonstrado por testes de neutralização cruzada e por reatividade com uma variedade de anticorpos monoclonais (BRATANICH et al., 1991; VOGEL et al., 2002; OLDONI et al., 2004). Desta forma, técnicas sorológicas ou imunológicas de rotina são incapazes de distinguir entre o BHV-1 e BHV-5. Essa relação sorológica entre os dois herpesvírus bovino reflete-se também em proteção cruzada in vivo (CASCIO et al., 1999; BELTR ̃̃̃ et al., 2000) e tem sido responsabilizada, em parte, pela baixa ocorrência da enfermidade neurológica pelo BHV-5 em regiões onde a infecção pelo BHV-1 é endêmica e/ou utiliza-se vacinação (CASCIO et al., 1999).

O diagnóstico laboratorial de infecções agudas pelo BHV-1 e BHV-5 é geralmente realizado através de testes sorológicos pareados (soroneutralização ou ELISA), isolamento viral ou microscopia eletrônica (HEUSCHELE \& CASTRO, 1992; KAHRS, 2001). Recentemente, a demora em se identificar a etiologia de um surto de enfermidade neurológica em bovinos na região central do Rio Grande do Sul, chamou a atenção para a necessidade do estabelecimento de técnicas rápidas de diagnóstico para essas viroses. O presente trabalho teve como objetivo adaptar e padronizar técnicas rápidas de diagnóstico de infecções pelo BHV-1 e BHV-5 com o uso de anticorpos monoclonais (AcMs) produzidos contra antígenos do BHV-5.

\section{MATERIAL E MÉTODOS}

Anticorpos monoclonais (AcMs) anteriormente produzidos contra antígenos de uma amostra brasileira do BHV-5 (OLDONI et al., 2004) foram utilizados na padronização/adaptação de técnicas rápidas de diagnóstico. Esses AcMs foram utilizados para a detecção de antígenos virais por imunofluorescência indireta (IFI) em: 1. células descamativas presentes em secreções nasais de bezerros inoculados com o BHV-1 e BHV-5; 2. impressões de cérebro de animais infectados naturalmente e 3 . células indicadoras, num teste de soroneutralização rápida.

\section{Células e vírus}

Todos os procedimentos de multiplicação e quantificação de vírus, soroneutralização (SN) e isolamento de vírus de secreções nasais foram realizados em células da linhagem de rim bovino CRIB (FLORES \& DONIS, 1995). As células foram cultivadas em meio essencial mínimo (MEM), contendo penicilina $(1,6 \mathrm{mg} / \mathrm{L})$, estreptomicina $(0,4 \mathrm{mg} / \mathrm{L})$, suplementado com soro fetal bovino a 5\%. Para a inoculação de animais, foram utilizadas alíquotas de uma amostra brasileira de BHV1 isolada de doença respiratória (SV-265) e de uma amostra brasileira de BHV-5 isolada de doença nervosa (SV-507) (DELHON et al., 2003).

Animais, inoculação e coleta de material

Dezesseis bezerros soronegativos para ambos os vírus foram inoculados pela via intranasal (BHV-5, n=10; BHV-1, n=6) com $10 \mathrm{~mL}$ de suspensão viral contendo aproximadamente $10^{6} \mathrm{DICC}_{50}$ (doses infectantes para 50\% dos cultivos celulares) dos respectivos vírus. Dois animais foram inoculados com MEM e permaneceram como controles. Durante 21 dias após a inoculação, os animais foram monitorados clinicamente e secreções nasais foram coletadas com o auxílio de swabs introduzidos na cavidade nasal e friccionados contra a mucosa. Os swabs eram então acondicionados em eppendorfs contendo $1 \mathrm{~mL}$ de MEM acrescido de 5 vezes a concentração de antibióticos descrita anteriormente e mantidos refrigerados até o processamento.

Ciência Rural, v.34, n.6, nov-dez, 2004. 


\section{Pesquisa de vírus nas secreções nasais}

Os swabs foram drenados no meio de transporte e os tubos centrifugados a aproximadamente $2000 \times$ g durante cinco minutos. O sobrenadante $(0,5 \mathrm{~mL})$ foi inoculado em monocamadas de células CRIB e submetido a três passagens com cinco dias de intervalo entre cada uma. Ao final de cada passagem, as células eram congeladas e descongeladas três vezes, e o sobrenadante reinoculado em cultivo celular. A replicação do vírus foi monitorada pela observação de efeito citopático (ECP).

\section{Pesquisa de antígenos virais em células descamativas (IFCD)}

O sedimento de células formado após centrifugação do meio onde estavam acondicionados os swabs foi ressuspendido em 100ml de MEM e a suspensão celular foi depositada em lâminas de microscopia do tipo multispot $(25 \mathrm{ml}$ por cavidade). Após secagem ao ar, as lâminas foram fixadas em acetona gelada durante 5 min e submetidas à imunofluorescência indireta (IFI), utilizando uma mistura de AcMs produzidos contra o BHV-5 como anticorpo primário, conforme descrito por OLDONI et al. (2004). Células CRIB infectadas ou não com o BHV-5 foram utilizadas como controles positivos e negativos, respectivamente. $\mathrm{O}$ isolamento de vírus e a pesquisa de antígenos em células descamativas foram realizadas por dois técnicos diferentes e os resultados comparados para os cálculos dos parâmetros de sensibilidade, especificidade, valores preditivo positivo e negativo de acordo com SOARES (2001). O índice de concordância (Kappa) foi calculado e interpretado de acordo com TOMA et al. (1999).

Pesquisa de antígenos virais em impressões de cérebro

A pesquisa de antígenos virais foi realizada em secções do cérebro de bezerros oriundos de casos naturais de enfermidade neurológica no Estado do Rio Grande do Sul. Para isso, impressões de diferentes secções do encéfalo foram feitas em lâminas de microscopia e submetidas à IFI conforme descrito acima.

\section{Sorologia}

A técnica de soroneutralização convencional (SN; HOUSE \& BAKER, 1971) foi modificada para obtenção dos resultados em 24 horas, resultando na técnica que foi denominada de SNR (soroneutralização rápida). Para isso, a replicação do vírus nas células indicadoras foi monitorada por IFI, realizada com AcMs após 20 horas de incubação. Os resultados da SNR foram comparados com a SN tradicional e com um kit comercial ELISA, utilizando- se 363 amostras de soro bovino enviados para diagnóstico sorológico. Essas amostras eram provenientes de animais não vacinados contra o BHV1 ou BHV-5.

Soroneutralização (SN) e soroneutralização rápida (SNR): alíquotas de soro $(50 \mathrm{ml})$, em duplicata, foram diluídas 1:2 em uma suspensão de vírus (BHV5 SV-507; 100-150 DICC $_{50}$ ) e incubadas a $37^{\circ} \mathrm{C}$ durante $2 \mathrm{~h}$ em placas de poliestireno de 96 cavidades. Após, uma suspensão de células CRIB (100ml) foi adicionada e misturada com a suspensão soro:vírus. Uma alíquota $(50 \mathrm{ml})$ dessa suspensão foi depositada em orifícios de lâminas de microscopia do tipo multispot, e as lâminas foram incubadas em uma câmara úmida a $37^{\circ} \mathrm{C}$ em estufa de $\mathrm{CO}_{2}$ Para a realização da SNR, o restante da suspensão soro:vírus:células foi mantido nas placas, que também foram incubadas nas mesmas condições. A leitura do teste de SNR foi realizada após $20 \mathrm{~h}$ de realizada a incubação com a mistura soro:vírus. As células indicadoras foram submetidas a IFI, conforme descrito anteriormente onde: a presença de antígenos virais indicava ausência de neutralização e a ausência destes indicava a presença de anticorpos com atividade neutralizante. A leitura do teste de SN foi realizada após $72 \mathrm{~h}$ de incubação, pela observação de ECP característico nas células. Amostras de soro anteriormente testadas e sabidamente negativas e positivas foram utilizadas como controles negativos e positivos, respectivamente. A leitura dos dois testes (SN e SNR) foi realizada por dois técnicos diferentes e os resultados foram comparados posteriormente.

ELISA: 363 amostras de soro submetidas à SN e SNR foram também testadas por um teste comercial do tipo ELISA indireto que detecta anticorpos contra o BHV-1 (HerdCheck, IDEXX Laboratories ${ }^{\mathrm{a}}$ ), de acordo com instruções do fabricante. Os resultados obtidos na SNR foram comparados com a SN tradicional e com o ELISA. Os parâmetros de sensibilidade, especificidade, valores preditivos positivos e negativos foram calculados de acordo com SOARES (2001) e o índice de concordância (Kappa) de acordo com TOMA et al. (1999).

\section{RESULTADOS E DISCUSSÃO}

Os resultados da pesquisa de vírus em secreções nasais e detecção de antígenos em células presentes nos swabs nasais coletados de bezerros inoculados com o BHV-1 ou BHV-5 estão apresentados na Tabela 1. De 203 amostras testadas, $182(89,9 \%)$ tiveram resultados concordantes (143 positivas; 39 negativas); 16 amostras $(7,9 \%)$ foram 
Tabela 1 - Detecção de vírus em secreções nasais e de antígenos virais em células descamativas do epitélio nasal de animais inoculados com os herpesvírus bovino tipos 1 e 5 (BHV-1 e BHV-5).

\begin{tabular}{|c|c|c|c|c|c|c|c|c|c|c|c|c|c|c|c|c|c|c|c|c|}
\hline \multirow{3}{*}{$\begin{array}{l}\text { Vírus/ } \\
\text { animal }\end{array}$} & \multicolumn{20}{|c|}{ Dia pós-inoculação (dpi) } \\
\hline & \multicolumn{2}{|c|}{0} & \multicolumn{2}{|c|}{1} & \multicolumn{2}{|c|}{$2-5$} & \multicolumn{2}{|c|}{6} & \multicolumn{2}{|c|}{7} & \multicolumn{2}{|c|}{8} & \multicolumn{2}{|c|}{9} & \multicolumn{2}{|c|}{10} & \multicolumn{2}{|c|}{11} & \multicolumn{2}{|c|}{12} \\
\hline & Iso $^{\mathrm{a}}$ & $\mathrm{IF}^{\mathrm{b}}$ & Iso & $\mathrm{IF}$ & Iso & $\mathrm{IF}$ & Iso & IF & Iso & $\mathrm{IF}$ & Iso & $\mathrm{IF}$ & Iso & $\mathrm{IF}$ & Iso & IF & Iso & IF & Iso & $\mathrm{IF}$ \\
\hline \multicolumn{21}{|l|}{ BHV-1 } \\
\hline 42 & $-{ }^{c}$ & - & - & + & + & & + & + & + & + & + & + & + & + & + & + & + & + & + & - \\
\hline 43 & - & - & $+^{\mathrm{d}}$ & + & + & + & + & + & - & + & - & - & - & + & - & - & - & + & - & - \\
\hline 44 & - & - & - & + & + & + & + & + & + & + & + & + & + & + & + & + & - & - & + & + \\
\hline 55 & - & - & + & + & + & + & + & + & + & + & - & + & - & + & - & - & - & + & - & - \\
\hline 56 & - & - & + & + & + & + & + & + & + & + & + & + & - & + & + & - & - & - & + & + \\
\hline 99 & - & - & + & + & + & + & + & $\mathrm{Sc}^{\mathrm{e}}$ & + & + & - & - & + & + & + & + & - & - & - & - \\
\hline \multicolumn{21}{|l|}{ BHV-5 } \\
\hline 47 & - & - & - & + & + & + & + & + & + & + & + & $\mathrm{sc}$ & + & $\mathrm{sc}$ & + & + & - & - & - & - \\
\hline 48 & - & - & + & + & + & + & + & + & + & + & + & + & + & + & + & + & + & + & - & - \\
\hline 49 & - & - & + & + & + & + & + & + & + & + & + & + & + & + & + & - & + & + & + & $\mathrm{sc}$ \\
\hline 57 & - & - & + & + & + & + & + & + & + & + & + & - & + & + & + & + & + & + & + & + \\
\hline 58 & - & - & + & + & + & + & + & $\mathrm{sc}$ & + & + & + & + & + & + & + & + & - & - & - & + \\
\hline 86 & - & - & - & + & + & + & + & + & + & + & + & + & + & + & + & + & + & + & + & + \\
\hline 2 & - & - & + & + & + & + & + & + & + & + & + & + & + & + & - & - & - & - & - & - \\
\hline 3 & - & - & + & + & + & + & + & + & + & + & + & - & + & + & - & - & - & - & - & - \\
\hline 4 & - & - & - & - & + & + & + & + & + & + & + & + & + & + & - & + & - & - & - & - \\
\hline 6 & - & - & + & + & + & + & + & + & + & + & + & + & + & + & - & + & - & + & - & + \\
\hline
\end{tabular}

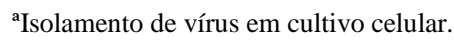

${ }^{\mathrm{b}}$ IF- Imunofluorescência indireta em células descamativas.

${ }^{\mathrm{c}}$ Negativo.

${ }^{\mathrm{d} P o s i t i v o}$

${ }^{\mathrm{e}}$ Sem célula. Nos dias 2, 3, 4 e 5, todas as amostras foram positivas nos dois testes.

positivas apenas na IFCD e 5 amostras $(2,5 \%)$ foram positivas apenas no isolamento viral. Considerandose a técnica de isolamento como padrão, a IFCD apresentou sensibilidade de $96,6 \%$; especificidade de $70,9 \%$; valor preditivo positivo de $89,9 \%$ e negativo de $88,6 \%$. A precisão foi de $89,6 \%$ e o índice de concordância (Kappa) foi de 0,72 , o que indica uma boa correlação entre as duas técnicas.

As discrepâncias observadas no dia 1 pós infecção (pi) entre a IFCD e o isolamento provavelmente devem-se à detecção de antígenos virais nas células antes de que algum efeito citopático pudesse ser observado ou que partículas víricas infectivas liberadas das células pudessem ser detectados. A partir do dia 8pi, algumas amostras positivas na IFCD foram negativas no isolamento (Tabela 1). Dentre as explicações possíveis para essa discrepância pode-se mencionar: 1. Diferenças na sensibilidade entre as técnicas; 2. Possível inativação da infectividade de partículas víricas durante o transporte e processamento das amostras (NETTLETON et al., 1983); 3. Presença de anticorpos neutralizantes nas secreções na fase tardia da infecção. Não obstante, deve ser ressaltado que na fase clínica da infecção, entre os dias 2 e 7pi, a concordância entre as técnicas foi de quase $100 \%$. Como a coleta e submissão de amostras para diagnóstico é geralmente realizada quando os animais apresentam sinais clínicos, a probabilidade de diagnóstico positivo pela IFCD nessa fase é igual ao isolamento. Esses resultados indicam que a detecção de antígenos em células descamativas presentes em secreções nasais coletadas com swabs representa uma alternativa para o diagnóstico de infecções agudas pelo BHV-1 e BHV5. Uma descrição dos achados clínicos, virológicos e sorológicos nos animais inoculados experimentalmente foi relatada por VOGEL et al. (2004).

Ciência Rural, v.34, n.6, nov-dez, 2004. 
O sucesso da técnica de IFCD depende muito da coleta adequada de material. A introdução profunda e fricção dos swabs contra a mucosa nasal é crítica, para assegurar-se da presença de boa quantidade de células no material coletado (NETTLETON et al., 1983; HEUSCHELE \& CASTRO, 1992). NETTLETON et al. (1983), ao examinarem 200 swabs coletados de 107 surtos suspeitos de IBR, obtiveram um número maior de resultados positivos no isolamento $(34,5 \%$ de amostras positivas) do que na imunofluorescência em células epiteliais $(14,5 \%)$. Uma explicação para parte dessa diferença encontrada provavelmente tenha sido a coleta inadequada de material. No presente trabalho, não foi possível interpretar-se o resultado da IFCD em algumas amostras, devido à ausência de células suficientes no material coletado. A coleta tardia de material no curso clínico da enfermidade, quando a secreção nasal é abundante e mucopurulenta, também dificulta a interpretação dos resultados do teste (NETTLETON et al., 1983).

O uso de AcMs na técnica de IFI permitiu a detecção e identificação de células positivas nos dois grupos de animais, com coloração intensa e sem reações inespecíficas (Figura 1A). Um estudo, utilizando um anticorpo policlonal ovino anti-BHV-1 marcado com fluoresceína, NETTLETON et al. (1983) necessitaram utilizar vários métodos de bloqueio de reações inespecíficas, além de vários controles diferentes, para assegurar-se da especificidade da reação. Mesmo assim, detectaram fluorescência inespecífica em células coletadas de alguns animais. Nesse sentido, o uso de AcMs preclude essas etapas e facilita a interpretação dos resultados, tornando o diagnóstico mais específico e confiável. Os resultados obtidos a partir de animais inoculados experimentalmente são promissores, no entanto se faz necessário validar esta técnica para uso em infecções naturais.

Em infecções naturais e experimentais, tanto o BHV-1 como o BHV-5 produzem sinais respiratórios durante a infecção aguda (MEYER et al., 2001). Nesses casos, a utilização de AcMs, que reagem com antígenos dos dois vírus, poderia ser utilizada em um primeiro teste baseado simplesmente na identificação do agente etiológico - herpesvírus bovino. No presente estudo, foi utilizada uma mistura de AcMs produzidas com o BHV-5, mas que reagem também com antígenos do BHV-1. Em caso de resultado positivo, a diferenciação entre BHV-1 e BHV-5 poderia ser realizada, em uma segunda etapa, pela utilização de um AcM (2F9) que reconhece apenas antígenos do BHV-5 (OLDONI et al., 2004).
Além da especificidade, outra vantagem da técnica de IFCD é a rapidez de obtenção dos resultados. Considerando-se a preparação das lâminas, fixação, execução das técnica de IFI, a técnica pode ser concluída em menos de duas horas. Em situações de surto, em que um diagnóstico etiológico ágil é necessário para direcionar as medidas a serem adotadas, esse método pode representar uma alternativa rápida e segura de diagnóstico. Nesse sentido, essa técnica foi recentemente utilizada no diagnóstico de um surto de enfermidade neurológica em bezerros no Rio Grande do Sul, em que o quadro clínico era atípico e tentativas de isolamento viral falharam. Antígenos do BHV-5 foram detectados em células epiteliais presentes em secreções nasais coletadas de um bezerro com sinais neurológicos. Em uma ocasião anterior, e também no presente surto, antígenos do BHV-5 foram detectados em secções do SNC de animais que apresentaram sinais neurológicos (Figura 1B). Nesses dois casos, houve confirmação posterior do diagnóstico através de isolamento do vírus.

O uso dos AcMs na técnica de IFI também permitiu a detecção de antígenos do BHV-5 nas células indicadoras utilizadas no teste de SN. Com isso, os resultados puderam ser obtidos em 24 horas $(2 \mathrm{~h}$ de incubação soro:vírus +20 horas de incubação com as células $+2 \mathrm{~h}$ para a realização da IFI). A redução do tempo de incubação (20h versus 72-96h) e a alteração na forma de monitoramento da replicação viral (detecção de antígenos virais versus $\mathrm{ECP)} \mathrm{não} \mathrm{trouxeram} \mathrm{prejuízos} \mathrm{à} \mathrm{confiabilidade} \mathrm{do}$ teste. Em comparação com a SN tradicional, a SNR apresentou sensibilidade de $97,3 \%$, especificidade de $95,5 \%$, valor preditivo positivo de $93,4 \%$, negativo de $98,2 \%$ e precisão de $96,2 \%$. O índice de concordância entre as duas técnicas foi excelente (índice Kappa de 0,92). Além de reduzir o tempo de obtenção dos resultados, a SNR permitiu o teste de amostras de soro que apresentaram toxicidade para as células indicadoras na SN tradicional, devido à longa incubação (72-96h).

Em um experimento paralelo, com o objetivo de verificar se a redução do tempo de incubação poderia resultar em prejuízo da sensibilidade do teste, foi realizada IFI nas células indicadoras em diferentes intervalos. Os resultados obtidos demonstraram a possibilidade de redução do tempo de incubação para até $12-14$ h, sem prejuízo da sensibilidade (dados não mostrados).

Quando comparada com um teste comercial ELISA, a SNR apresentou 


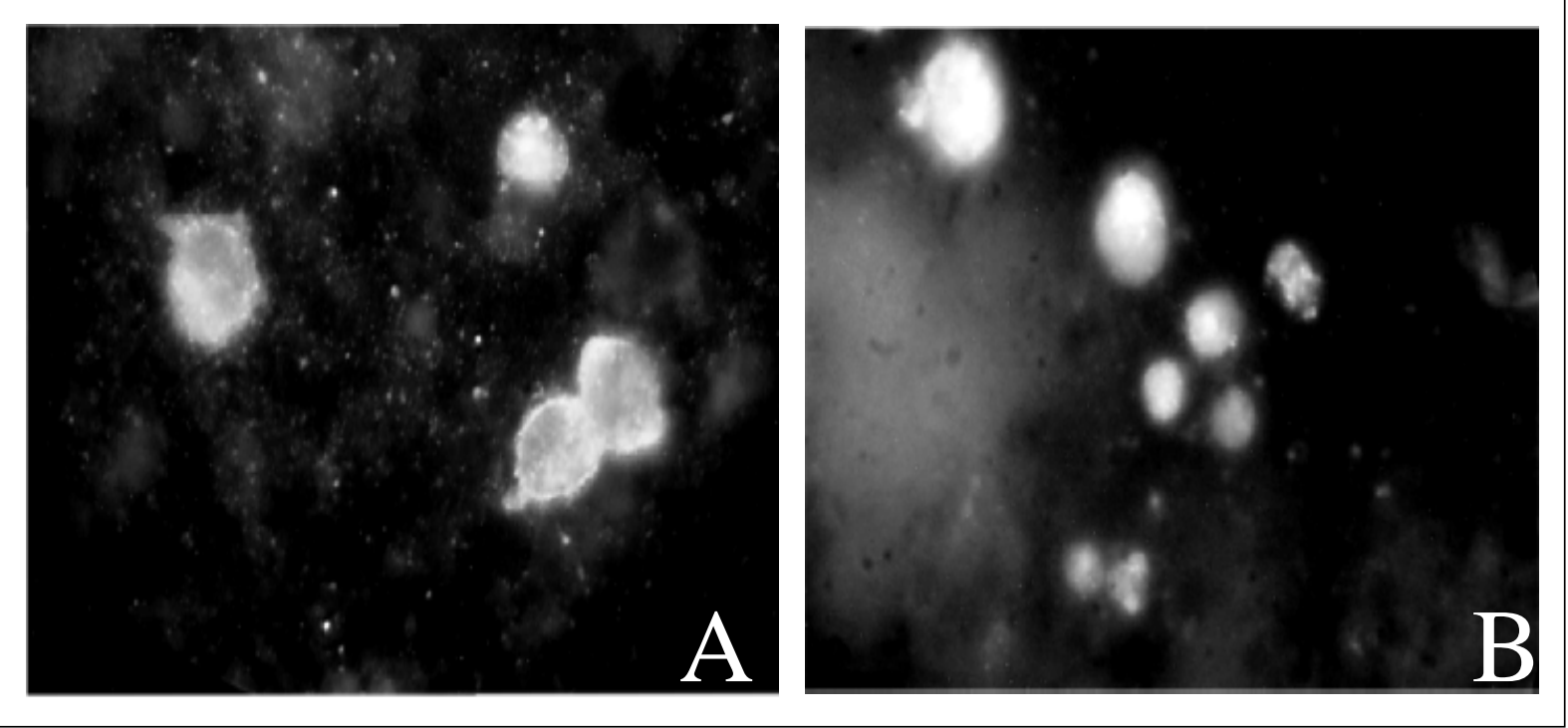

Figura 1 - Imunofluorescência de células descamativas presentes em secreções nasais de um bezerro infectado experimentalmente com o herpesvírus bovino tipo 5 (BHV-5) (1A); e em impressão de bulbo olfatório de um bezerro infectado naturalmente (1B). Uma mistura de anticorpos monoclonais (AcMs) contra o BHV-5 foi utilizada como anticorpo primário. Contra-coloração Evans Blue. Magnificação: 320x.

sensibilidade de $94,7 \%$, especificidade de $97,3 \%$, valor preditivo positivo de $97,0 \%$, negativo de $95,3 \%$ e precisão de $96,1 \%$ (Tabela 2 ). O índice de concordância foi de 0,92 , o que indica uma associação excelente entre as duas técnicas. Embora mais trabalhosa e demorada que o ELISA, a técnica de SNR possui um custo menor do que os kits importados e pode encontrar aplicações em laboratórios que não dispõe de equipamentos para o teste imunoenzimático. Além disso, a SNR pode ter aplicação importante na realização de testes sorológicos pareados, nos quais é necessário quantificar-se e comparar os títulos de anticorpos da fase aguda e convalescente, o que não é viável se fazer com os testes ELISA comerciais.

Em resumo, os AcMs produzidos com uma amostra de BHV-5, e que reagem também com antígenos do BHV-1 (OLDONI et al., 2004), demonstraram a sua utilidade para emprego em testes rápidos de diagnóstico das infecções por esses vírus. A sua utilização na detecção de antígenos em células descamativas, impressões de cérebro ou em células indicadoras na $\mathrm{SN}$ pode contribuir para um diagnóstico mais rápido e confiável de infecções pelo BHV-1 e BHV-5. A detecção de antígenos em células descamativas do epitélio nasal pode representar uma alternativa importante também no diagnóstico de outras infecções respiratórias víricas, em especial pelo vírus respiratório sincicial bovino (BRSV), cujo isolamento é dificultado pela extrema labilidade do agente em condições ambientais (BAKER, 1986).

\section{FONTES DE AQUISIÇÃO}

${ }^{a}$ IDEXX Laboratories, Inc. Westbrook, Maine, USA.

Tabela 2 - Resultados dos testes de soro-neutralização rápida (SNR), soro-neutralização (SN) e ELISA na detecção de anticorpos que reagem com o herpesvírus bovino tipo 5 (BHV-5) em amostras de soro bovino.

\begin{tabular}{cccccccc}
\hline & \multicolumn{2}{c}{ SN } & \multicolumn{3}{c}{ ELISA } \\
\hline & & Positivos & Negativos & Total & Positivos & Negativos & Total \\
\hline SNR & Positivos & 186 & 13 & 199 & 164 & 5 & 169 \\
& Negativos & 5 & 279 & 284 & 9 & 185 & 194 \\
& Total & 191 & 292 & 483 & 173 & 190 & 363 \\
\hline
\end{tabular}

Ciência Rural, v.34, n.6, nov-dez, 2004. 


\section{REFERÊNCIAS BIBLIOGRÁFICAS}

BAKER, J. Bovine respiratory syncytial virus: immunopathogenesis, clinical signs, diagnosis and prevention. Infect Dis Food Anim, v.8, p.62-68, 1986.

BARTHA, A. et al. Occurrence of encephalomyelitis caused by infectious bovine rhinotracheitis virus in calves in Hungary. Acta Vet Acad Scient Hung, v.19, p.145-151, 1969.

BELTRÃO, N. et al. Infecção aguda e enfermidade neurológica pelo herpesvírus bovino tipo 5 (BHV-5): coelhos como modelo experimental. Pesq Vet Bras, v.20, n.4, p.144-150, 2000.

BRATANICH, A.C. et al. Comparative studies of BHV-1 variants by in vivo and in vitro tests. Zbl Vet Med B, v.38, p.41-48, 1991.

CARRILLO, B.J. et al. Meningoencephalitis caused by IBR virus in calves in Argentina. Zbl Vet Med B, v.30, p.327-332, 1983.

CASCIO, K.E. et al. Encephalitis induced by bovine herpesvirus 5 and protection by prior vaccination or infection with bovine herpesvirus 1. J Vet Diagn Invest, v.11, p.134-139, 1999.

DELHON, G. et al. Genome of bovine herpesvirus 5. J Virol, v.77, n.19, p.10339-10347, 2003.

EUGSTER, A.K. et al. Herpesvirus encephalitis in range calves. Proc Ann Mtg Am Assoc Vet Lab Diagn, v.17, p.267-290, 1974.

FRENCH, E.L. A specific virus encephalitis in calves: isolation and characterization of the causal agent. Aust Vet J, v.38, p.216221,1962

FLORES, E.F.; DONIS, R.O. Isolation and characterization of a bovine cell line resistant to infection with the pestivirus bovine viral diarrhea virus (BVDV). Virology, v.208, p.565-575, 1995.

HEUSCHELE, W.P.; CASTRO, A.E. Viral diagnosis: general considerations. In: CASTRO, A.E; HEUSCHELE, W.P. Veterinary diagnostic virology. St. Louis : Mosby Year Book, 1992. p.1-16.

HOUSE, J.A.; BAKER, J.A Bovine herpesvirus IBR-IPV. The antibody virus neutralization reaction. Cornell Vet, n.61, p.320$335,1971$.
KAHRS, R.F. Infectious bovine rhinotracheitis and infectious vulvovaginitis. In:_. Viral diseases of cattle. 2.ed. Ames : Iowa State University, 2001. p.159-170.

LOVATO, L.T. et al. Herpesvírus bovino tipo 1 (HVB-1): inquérito soro-epidemiológico no rebanho leiteiro do Estado do Rio Grande do Sul, Brasil. Ciênc Rural, v.25, n.3, p.425-430, 1995

MEYER, G. et al. Comparative pathogenesis of acute and latent infections of calves with bovine herpesvirus types 1 and 5. Arch Virol, v.146, p.633-652, 2001.

NETTLETON, P.F. et al. Evaluation of an immunofluorescent test for the rapid diagnosis of field infections of infectious bovine rhinotracheitis. Vet Rec, v.112, p.298-300, 1983

OLDONI, I. et al. Production and characterization of monoclonal antibodies to a Brazilian bovine herpesvirus type 5 (BHV-5). Braz J Med Biol Res, 2004. (no prelo)

ROIZMAN, B. et al. The family Herpesviridae: an update. Arch Virol, v.123, p.425-449, 1992.

SOARES, C.O. Princípios, padronização e validação de provas sorológicas. In: MADRUGA, C.R.; ARAÚJO, F.R.; SOARES, C.O. Imunodiagnóstico em medicina veterinária. Campo Grande: EMBRAPA, 2001. Cap.6, p.145-178.

STUDDERT, M.J. Bovine encephalitis. Vet Rec, v.125, p.584, 1989.

TOMA, B. et al. Dictionary of veterinary epidemiology. Ames: Iowa State University, 1999. 284p.

VOGEL, F.S.F. et al. Atividade neutralizante anti-herpesvírus bovino tipos 1 (BHV-5) e 5 (BHV-5) no soro de bovinos imunizados com vacinas contra o BHV-1. Ciênc Rural, v.32, n.5, p.881-883, 2002 .

VOGEL, F.S.F. et al. Replicação e excreção viral durante a infecção aguda e após reativação da infecção latente pelos herpesvírus bovino tipos 1 (BHV-1) e 5 (BHV-5). Cienc Rural, v.34 (no prelo) 2004.

WEIBLEN, R. et al. Bovine meningoencephalitis from IBR virus. Vet Rec, v.124, p.666-667, 1989. 